\title{
Shift Process Analysis of AMT without Synchronizer Based on Three-phase Induction Motor
}

\author{
Yunxia Li, Zengcai Wang ${ }^{1}$ and Xiaoyan Cong \\ School of Mechanical Engineering, Shandong University, China \\ ldyffr@126.com,wangzc@sdu.edu.cn,195781302@qq.com
}

\begin{abstract}
In order to achieve synchronous shift on heavy-duty AMT (Automated Mechanical Transmission) without synchronizer, shift process analysis based on three-phase induction motor is proposed in the paper. On the basis of analysis for the speed loss of the transmission output shaft during shift process, the synchronous shift control strategy for AMT without synchronizer driven by three-phase induction motor is put forward for both upshift and downshift program. Estimation algorithms of the load equivalent inertia and the load equivalent resistance torque at the transmission output shaft are proposed to best meet the synchronous shift control. In view of similarity between the start-up process of the vehicle and that of the belt conveyor, AMT without synchronizer based on three-phase induction motor is applied to driving the belt conveyor. Simulation results prove that the strategy of synchronous shift control is effective during upshift process and downshift process.
\end{abstract}

Keywords: three-phase induction motor; automated mechanical transmission; shift process; synchronous control

\section{Introduction}

Transmission is a speed and power changing device of the vehicle which changes the driving torque both in magnitude and directions to best meet various driving conditions [1-2]. As is well known, the synchronizer-type transmission has been developed from the nonsynchronizer-type transmission. The former has a history of more than half a century which makes it easier to shift, but it still has some difficult technology problems that it cannot be widely used in heavy-duty vehicles. Compared with other types of automatic transmission, AMT has become a principal selection for heavy truck because it has some advantages such as low cost, high efficiency and large torque [3-5]. Therefore, it is of great importance to research heavy-duty AMT without synchronizer.

With the help of synchronizer, the transmission with synchronizer can achieve synchronous shift easily. By contrast, the transmission without synchronizer can achieve synchronous shift only if the engagement sleeve and the sliding gears have the same speed. So, the synchronous shift becomes complicated for heavy-duty AMT without synchronizer.

\footnotetext{
* Project supported by the National Nature Science Foundation of China (No. 51174126)

${ }^{1}$ Corresponding author.

Email addresses: wangzc@sdu.edu.cn (Zengcai WANG)
} 


\section{Shift Model of Transmission}

In order to simplify the analysis, assumptions are put forward as follows. The friction losses between gears are ignored. The pressure of either pneumatic system or hydraulic system is stable for the purpose of stabilized forces delivered by AMT actors. The influences of wear and temperature on the friction force between the clutch disk and the pressure plate are ignored.

Schematic diagram of shift model between two adjacent gears is shown in figure 1. One sliding gear is connected to the output shaft by means of an engagement sleeve. The engagement sleeve is controlled by the shifting fork which is controlled by the shift gear. It is in neutral position if the engagement sleeve is not meshed with a sliding gear. Two sliding gears can not be meshed with the engagement sleeve at the same time. For this reason, a new gear position is coming up only after the engagement sleeve is disengaged from the former one.

The transmission output speed and the transmission input speed are considered as the shift parameters. TCU (Transmission Control Unit) switches to the upshift program under the circumstance that the transmission input speed reaches the rated speed of the three-phase induction motor and the transmission output speed reaches the target value determined by the rated speed of the three-phase induction motor and the gear ratio. TCU switches to the downshift program under the condition that the transmission input speed reduces to the threshold value and the transmission output speed drops to the value determined by the rated speed of the three-phase induction motor and the gear ratio of lower gear. A simplified shift model of two adjacent gears controlled by an engagement sleeve is discussed in Figure 1. The current gear is number $\mathrm{j}$ gear which is going to be shifted to number $\mathrm{j}+1$ gear.

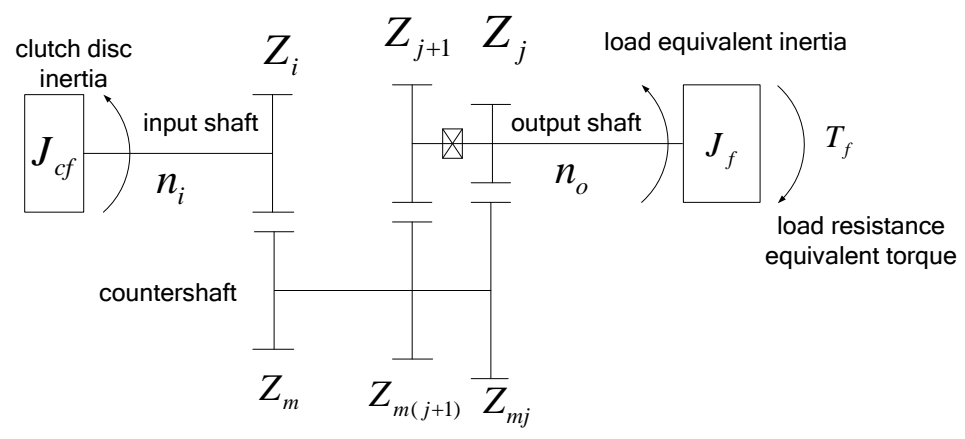

\section{Figure 1. Simplified Shift Model from Number J Gear to Number J+1 Gear}

The speed relationship between the output shaft and the input shaft under number $\mathrm{j}$ gear is given in equation (1).

$$
n_{o}=\frac{n_{i}}{i_{j}}=\frac{z_{j}}{z_{m j}} \cdot \frac{z_{m}}{z_{i}} n_{i}
$$

To meet the requirement of synchronous shift, the transmission output speed under the latter gear position and that under the former gear position should be equal. Therefore, the speed relationship between the output shaft and the input shaft under number $\mathrm{j}+1$ gear is given in equation (2).

$$
n_{o}=\frac{n_{i}}{i_{j+1}}=\frac{z_{j+1}}{z_{m(j+1)}} \cdot \frac{z_{m}}{z_{i}} n_{i}
$$


Where $n_{o}$ is the transmission output speed, $n_{i}$ is the transmission input speed, $i_{j}$ is the gear ratio of number $\mathrm{j}$ gear, $z_{i}$ is the number of teeth on the input shaft gear, $z_{m}$ is the number of teeth on the countershaft-mesh gear which meshes with the input shaft gear constantly, $z_{m j}$ and $z_{m(j+1)}$ are the number of teeth on the countershaft gears associated with number $\mathrm{j}$ gear position and number $\mathrm{j}+1$ gear position respectively, $z_{j}$ and $z_{j+1}$ are the number of teeth of the sliding gears associated with number $j$ gear position and number $j+1$ gear position on the output shaft separately.

The shift process of AMT without synchronizer can be divided into six stages, including clutch disengaging, putting the gears in neutral, selecting gear, synchronizing control, shifting gear, and clutch engaging. The transmission must be in neutral position when the transmission is in selecting gear stage. Under the influence of the load inertia and the load resistance, the transmission output speed will slow down during clutch disengagement. That is to say, the speed loss of the transmission output shaft will appear during shift process. In this case, the input shaft speed will remain the same value if the friction loss between the input shaft and the rolling bear is ignored, while the output shaft speed will slow down. So, when it is time to shift, the speed relationship between the input shaft and the output shaft can no longer meet the new gear's requirement. The total time of the shift process will be lengthened and the transmission will suffer a more violent shock if the input shaft is not in control during shift process.

The differential equation for the transmission output speed during selecting gear stage can be obtained in equation (3).

$$
\frac{d n_{o}}{d t}=\frac{30 T_{f}}{J_{f} \pi}
$$

Where $J_{f}$ is the load equivalent inertia at the transmission output shaft, $T_{f}$ is the load equivalent resistance torque at the transmission output shaft.

So, the speed loss of the output shaft during selecting gear stage can be gotten in equation (4).

$$
\Delta n_{\text {oloss }}=\frac{30 T_{f}}{J_{f} \pi} \Delta t_{s}
$$

Where $\Delta t_{s}$ and $\Delta n_{\text {oloos }}$ are the time of selecting gear stage and the speed loss of the output shaft respectively.

\section{Synchronization Analyses and Synchronous Shift Control Strategy}

How to achieve synchronous shift is the key difficult problem of the synchronous shift control algorithm for heavy-duty AMT without synchronizer. The gear ratio and the speed loss of the output shaft are different under different gear position or different working condition, which makes it complicated to achieve synchronous shift during shift process. For this reason, it is important to research synchronous control methods for AMT without synchronizer.

\subsection{Synchronization Analysis and Synchronous Control Strategy for Up Shift Process}

3.1.1 Synchronization Analysis for Up Shift Process: As is shown in Figure 2, the schematic diagram of speed synchronization during upshift process provides an interrelation 
of the input shaft and the output shaft. The current gear position is number $j$ which is going to be shifted to number $\mathrm{j}+1 \mathrm{~A}$ point is the theory shift point under number $\mathrm{j}$ gear while its corresponding theory working point is B point under number $j+1$ gear. Based on the above analysis for the speed loss of the output shaft, the actual theory shift point changes from $\mathrm{A}$ point to $\mathrm{C}$ point under the influences of the load inertia and the load resistance during selecting gear stage. The corresponding actual working point changes from $\mathrm{B}$ point to $\mathrm{D}$ point under number $\mathrm{j}+1$ gear. The speed difference of the input shaft between A point and $\mathrm{D}$ point is the decrease for the purpose of synchronous shift which should be taken measures to control.

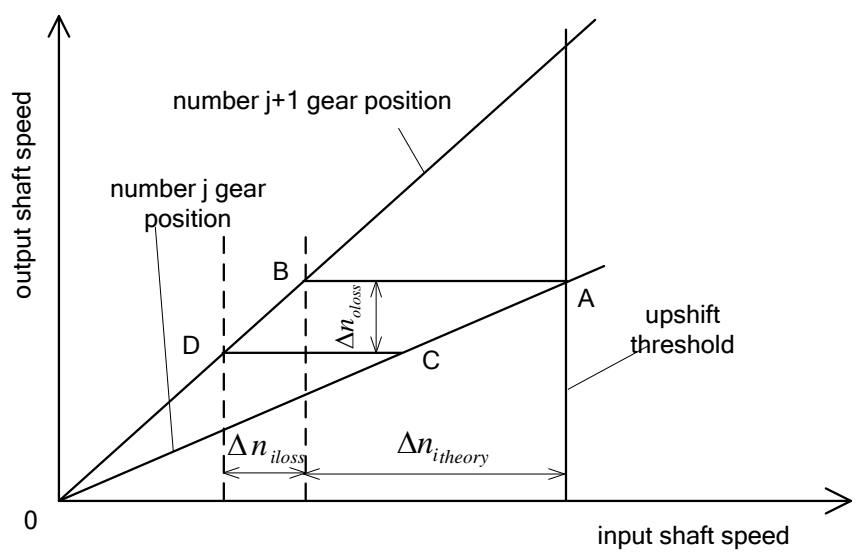

\section{Figure 2. Schematic Diagram of Speed Synchronization During Up Shift Process}

The theory speed difference of the input shaft between the theory shift point under number $\mathrm{j}$ gear and the theory working point under number $\mathrm{j}+1$ gear can be describes as:

$$
\Delta n_{i \text { theory }}=n_{o j} i_{j}-n_{o j} i_{j+1}
$$

Where $\Delta n_{\text {itheory }}$ is the theory speed difference of the input shaft between the theory shift point $\mathrm{A}$ and the theory working point $\mathrm{B}, n_{o j}$ is the output shaft speed at the theory shift point $\mathrm{A}, i_{j}$ and $i_{j+1}$ are the gear ratios under number $\mathrm{j}$ gear and number $\mathrm{j}+1$ gear respectively.

Consequently, the speed difference of the input shaft between the theory working point and the actual working point under number $\mathrm{j}+1$ gear can be described as:

$$
\Delta n_{\text {iloss }}=\Delta n_{\text {oloss }} i_{j+1}
$$

As is shown in Figure 2, the decrease in the input shaft speed between the theory shift point and the actual working point consists of $\Delta n_{\text {itheory }}$ and $\Delta n_{\text {iloss }}$ when it's time to shift from number $\mathrm{j}$ gear to number $\mathrm{j}+1$ gear. So, the speed difference of the input shaft between the theory point and the actual working point can be obtained as:

$$
\Delta n_{i j}=\Delta n_{\text {itheory }}+\Delta n_{\text {iloss }}=n_{o j}\left(i_{j}-i_{j+1}\right)+\frac{30 T_{f} \Delta t_{s} i_{j+1}}{J_{f} \pi}
$$


Where $\Delta n_{i j}$ is the speed difference of the input shaft between the theory shift point $\mathrm{A}$ and the actual working point $\mathrm{D}, \Delta n_{\text {iloss }}$ is the speed difference of the input shaft between the working point $\mathrm{B}$ and the actual working point $\mathrm{D}$.

3.1.2 Synchronous Control Strategy for the Input Shaft: Based on the above analysis, the input shaft must be slowed down and meet the synchronization requirement so as to decrease the time of the shift process and achieve synchronous shift. As is shown in equation (7), the control quantity of the input shaft speed varies owing to different gear position. It needs a brake device to slow down the input shaft. Of course, the braking time is different under different gear position and different load conditions even if the braking torque is same. Additionally, the inertia at the input shaft is very small that the input shaft can be slowed down quickly under the braking torque. In a sense, the braking time should be as short as possible for a short shifting time. It is best that the braking time of the input shaft is less than the time of selecting gear. Consequently, the matching relationship between the input shaft speed and the output shaft speed should be controlled precisely.

Assuming that the braking torque is constant, the braking time of the input shaft can be gotten from formula (8).

$$
t_{\text {brake }}=\frac{J_{c f} 2 \pi \Delta n_{i j}}{60 T_{t b}}=\frac{J_{c f} \pi \Delta n_{i j}}{30 T_{t b}}
$$

Where $t_{\text {brake }}$ is the braking time of the input shaft for upshift, $J_{c f}$ is the inertia at the input shaft, and $T_{t b}$ is the braking torque delivered by AMT brake.

\subsection{Synchronization Analysis and Synchronous Control Strategy for Downshift Process}

3.2.1 Synchronization Analysis for Downshift Process: As is shown in Figure 3, the schematic diagram of speed synchronization during downshift process offers an interrelation of the input shaft speed and the output shaft speed. The current gear position is number $\mathrm{j}$ which will be shifted to number $\mathrm{j}-1$. A point is the theory shift point under number $\mathrm{j}$ gear while its corresponding theory working point is B point under number $\mathrm{j}-1$ gear. The actual theory shift point changes from A point to $\mathrm{C}$ point under the influences of the load inertia and the load resistance during selecting gear stage. The corresponding actual working point changes from $B$ point to $D$ point under number $\mathrm{j}-1$ gear. The speed difference of the input shaft between A point and D point is the increase required to control for synchronous shift. In the process of shift, the induction motor can no longer drive the input shaft after the clutch is disengaged which makes the speed increase of the input shaft become difficult. 


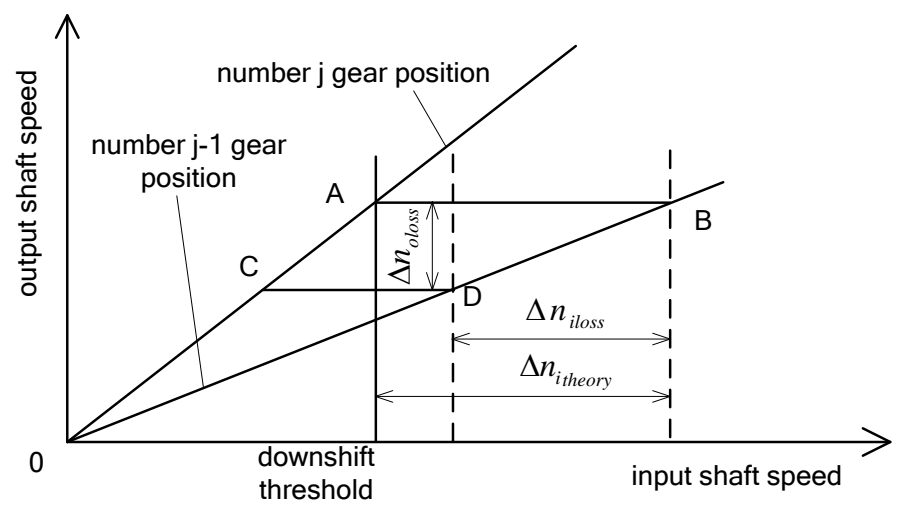

Figure 3. Schematic Diagram of Speed Synchronization During Downshift Process

As is similar to the analysis for upshift process, the theory speed difference of the input shaft between the theory downshift point under number $\mathrm{j}$ gear and the theory working point under number j-1 gear can be described as follows.

$$
\Delta n_{i t h e o r y}=n_{o j} i_{j-1}-n_{o j} i_{j}
$$

Where $i_{j-1}$ is the gear ratio under number $\mathrm{j}-1$ gear.

The speed loss of the input shaft between the theory working point and the actual working point under number j-1 gear can be described as:

$$
\Delta n_{\text {iloss }}=\Delta n_{\text {oloss }} i_{j-1}
$$

The speed difference of the input shaft speed between the theory shift point and the actual working point can be obtained from equation (9) and equation (10). It can be described as:

$$
\Delta n_{i j}^{\prime}=\Delta n_{\text {itheory }}-\Delta n_{\text {iloss }}=n_{o j}\left(i_{j-1}-i_{j}\right)-\frac{30 T_{f} \Delta t_{s} i_{j-1}}{J_{f} \pi}
$$

Where $\Delta n_{i j}^{\prime}$ is the speed difference of the input shaft between the theory shift point A under number $\mathrm{j}$ gear and the actual working point $\mathrm{D}$ under number $\mathrm{j}-1$ gear.

3.2.2 Synchronous Control Strategy for Downshift Process: On the basis of synchronization analysis above, two methods are discussed to realize synchronous downshift as below.

The first method proposed is that the input shaft can meet the requirement of synchronous downshift by waiting for slowing down the output shaft when the value of $\Delta n_{i j}^{\prime}$ is zero. That is to say, there is a particular moment that the theory speed difference of the input shaft between the theory downshift point $\mathrm{A}$ and the theory working point $\mathrm{B}$ is equal to the speed loss of the input shaft between the theory working point B and the actual working point $\mathrm{D}$. But it makes the time of selecting gear stage longer because it needs time to slow down the output shaft. By the use of the speed signals from the input shaft speed sensor and the output shaft speed sensor, the synchronous downshift can be achieved if their speed signals meet the 
gear ratio under number $\mathrm{j}-1$ gear position. The main problem of this method is that the shifting time will be longer.

The second method proposed for synchronous downshift is to operate the clutch twice that the speed increase of the input shaft can be achieved to meet the requirement of downshift. Under the condition of the first clutch disengaging, the speed of the clutch active part can reach the synchronous speed of the three-phase induction motor quickly. The first clutch engaging is adopted during selecting gear stage that the input shaft can be speeded up quickly with the help of the clutch control torque driven by the three-phase induction motor because the clutch disk moment of inertia is small. In order to reduce the time of downshift process, a best way is that the time for accelerating the input shaft is less than the time of selecting gear. After the input shaft's acceleration, the second clutch disengaging is adopted to cut off the power to prepare for shifting gear. It is time to downshift when the matching relationship between the input shaft speed and the output shaft speed are in the range of synchronization requirement. The second clutch engaging is operated after the completion of shifting gear.

Based on the second method, the time for accelerating the input shaft can be gotten in equation (12).

$$
t_{d}=\frac{J_{c f} \Delta n_{i j}^{\prime} \pi}{30 T_{c d}}
$$

Where $t_{d}$ is the time for accelerating the input shaft for downshift, $T_{c d}$ is the clutch control torque for accelerating the input shaft.

Assuming that the clutch control torque is constant during the first clutch engaging, the time for accelerating the input shaft for downshift is only related to the speed difference of the input shaft between the theory shift point and the actual working point which can be seen from equation (12). In theory, the second method is feasible which will make the clutch control be complicated during downshift process.

\section{Estimation Algorithms of the Load Equivalent Inertia and the Load Equivalent Resistance at the Transmission Output Shaft}

The load inertia and the load resistance torque are different under different working conditions that the speed control quantity of the input shaft is different which can be seen from equation (7) and equation (11). For heavy-duty transmission, the load changes greatly that the load equivalent inertia and the load equivalent resistance torque at the transmission output shaft will also change greatly. In view of similarity between the start-up process of the belt conveyor and that of the vehicle, heavy-duty AMT without synchronizer based on threephase induction motor is used to start belt conveyor softly in this paper which is a new softstarting device for belt conveyor. Simplified model of the drive line for belt conveyor's soft starting based on AMT is shown in Figure 4. For belt conveyor, the variation ranges of the load inertia and the load resistance torque are also large. So, it is necessary to estimate these parameters for AMT to improve shift characteristics. 


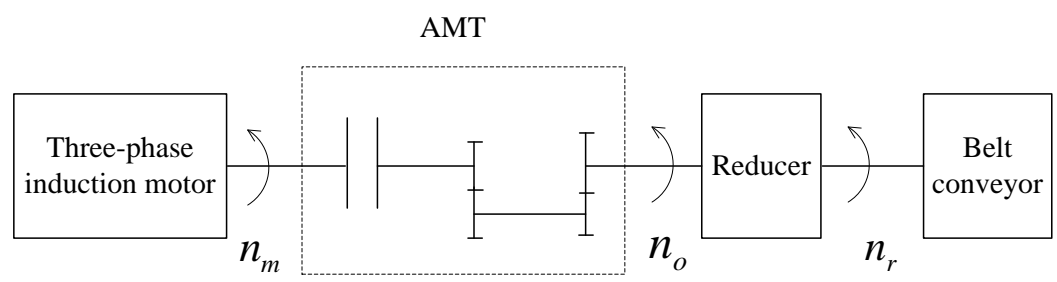

Figure 4. Simplified Model of the Drive Line for Belt Conveyor's Soft Starting Based on AMT

\subsection{Estimation Algorithm of the Load Equivalent Resistance Torque at the Transmission Output Shaft}

The biggest torque delivered by the clutch can be obtained from the relationship between the pressing force delivered by the pressure plate and the clutch cylinder displacement. The clutch cylinder displacement is related to the release bearing displacement by the lever ratio of the release fork. The clutch half engagement point is a position of the release bearing where the torque transmitted by the clutch is equal to the load equivalent resistance torque at the transmission input shaft [6-9]. As a result, the clutch half engagement joint can be used to estimate the load equivalent resistance torque at the transmission output shaft by mean of the gear ratio of the previous gear. In the process of the clutch engaging, the load acceleration will be greater than zero when the clutch control torque is greater than the load equivalent resistance torque at the input shaft. Therefore, the load equivalent resistance at the transmission output shaft can be estimated by means of the half engagement joint which can be expressed as:

$$
T_{f}=T_{c}\left(x_{c d}\right) \eta_{g} i_{g}
$$

Where $x_{c d}$ is the clutch cylinder displacement, $T_{c}\left(x_{c d}\right)$ is the clutch control torque related to the clutch cylinder displacement, $\eta_{g}$ and $i_{g}$ are the mechanical efficiency and the gear ratio of the transmission respectively.

\subsection{Estimation Algorithm of the Equivalent Inertia at the Transmission Output Shaft}

The running resistance of the belt conveyor can be described as:

$$
\sum F=F_{H}+F_{N}+F_{S t}+F_{S}
$$

Where $F_{H}$ is primary resistance, $F_{N}$ is additional resistance, $F_{S t}$ is hoist resistance, and $F_{S}$ is special kind of resistance.

The equivalent resistance torque at the transmission output shaft can be obtained as:

$$
T_{f}=\frac{\sum F \cdot r}{i_{0} \eta_{0}}
$$

Where $i_{0}$ and $\eta_{0}$ are the gear ratio and the mechanical efficiency of the reducer respectively.

By the use of conversation of energy, the equivalent inertia can be gotten in equation (16). 


$$
\frac{1}{2} \frac{J_{c} v^{2}}{r^{2}}+\frac{1}{2} \frac{J_{r} i_{0}^{2} v^{2} \eta_{0}}{r^{2}}+\frac{1}{2} \frac{J_{t o} i_{0}^{2} v^{2} \eta_{0}}{r^{2}}=\frac{1}{2} \frac{J_{f} i_{0}^{2} v^{2} \eta_{0}}{r^{2}}
$$

Where the first item on the left is the conveyor's kinetic energy at the driving pulley, the second item on the left is the reducer's kinetic energy, the third item on the left is the kinetic energy of the transmission output shaft, and the item on the right is the sum of the load equivalent kinetic energy and the kinetic energy of the transmission output shaft.

As a result, the load equivalent inertia at the transmission output shaft can be gotten as:

$$
J_{f}=\frac{J_{c}}{i_{0}^{2} \eta_{0}}+J_{r}+J_{t o}
$$

Where $J_{c}, J_{r}, J_{t o}, J_{f}$ are the conveyor's inertia, the reducer's inertia, the transmission output shaft's inertia and the load equivalent inertia at the transmission output shaft respectively.

Here, the clutch wear is ignored that the clutch cylinder displacement is regarded as the only influence on the clutch control torque. As is known, there is a nonlinear relationship between the clutch control torque and the clutch cylinder displacement which can be gotten through the experiment.

The relationship between the clutch control torque and the clutch cylinder displacement (or the release bearing displacement) can be described as:

$$
T_{c}=T_{c}\left(k x_{r b}\right)=T_{c}\left(x_{c d}\right)
$$

Where $x_{r b}$ is the release bearing displacement, $x_{c d}$ is the clutch cylinder displacement, and $k$ is the lever ratio of the clutch release fork which is the ratio between $x_{c d}$ and $x_{r b}$.

The angular acceleration at the transmission output shaft during the clutch engagement is given in equation (19):

$$
\frac{d^{2} \varphi}{d t^{2}}=\frac{T_{c} i_{g} \eta_{g}-T_{f}}{J_{c f} i_{g}^{2}+J_{f}}
$$

The above expression can be converted into the following expression:

$$
J_{f}=\frac{T_{c} i_{g} \eta_{g}-T_{f}}{\frac{d^{2} \varphi}{d t^{2}}}-J_{c f} i_{g}^{2}
$$

The equation (20) is the estimation algorithm of the load equivalent inertia at the transmission output shaft. The angular acceleration at the output shaft can be measured by the angular sensor or be calculated by the output shaft speed. On the basis of the estimation of the load equivalent resistance torque at the transmission output shaft, the load equivalent inertia at the transmission output shaft can be estimated on condition that the parameters such as the gear ratio, the mechanical efficiency and the input shaft inertia are known.

Several sets of data related to equation (20) are collected to calculate the load equivalent inertia. The average of their calculated results is regarded as the estimation value. The average can be described as: 


$$
E\left(J_{f}\right)=\frac{1}{n} \sum_{i=1}^{n} J_{f}(n t)
$$

Where $t$ is the sampling interval time, $J_{f}(n t)$ is the calculated value of the load equivalent inertia at the moment of $n t$ after the half engagement joint, $E\left(J_{f}\right)$ is the estimation value of the load equivalent inertia.

\section{Synchronous Shift Steps}

In addition to the gear ratio and the output shaft speed at the theory shift point, the speed control quantity of the input shaft is related to the load equivalent inertia and the load equivalent resistance torque during either upshift process or downshift process. Synchronous shift control must be based on the estimations of the two parameters above. In the light of analyses for synchronous shift, the main control steps are listed as below.

Step 1. Test the current gear information and estimate the load equivalent inertia and the load equivalent resistance torque.

Step 2. Judge the shift point and determine upshift or downshift.

Step 3. Operate clutch disengaging.

Step 4. Put the gears in neutral and operate selecting gear.

Step 5. Calculate the speed control quantity of the input shaft.

Step 6. Carry out synchronous control.

Step 7. Judge the range of synchronization.

Step 8. Operate shifting gear.

Step 9. Operate clutch engaging.

\section{Simulation Result}

Belt conveyor's soft starting demands that belt acceleration should be less than $0.3 \mathrm{~m} / \mathrm{s} / \mathrm{s}$ which can be controlled by the clutch control torque. Driven by three-phase induction motor with $110 \mathrm{KW}$ power, based on heavy-duty AMT without synchronizer, simulation analyses for upshift process from first gear to second gear and downshift process from eighth gear to seventh gear are given under the conditions with synchronous control and without synchronous control respectively. Belt velocity is adopted as a parameter for shift schedule which can be transformed to the input shaft speed by the gear ratio. Another parameter for shift schedule is the input shaft speed. The main parameters such as belt velocity, belt acceleration and transmission output speed are analyzed. The curves during upshift process from first gear to second gear are shown in Figure 5. The curves during downshift process from eighth gear to seventh gear are shown in Figure 6. 

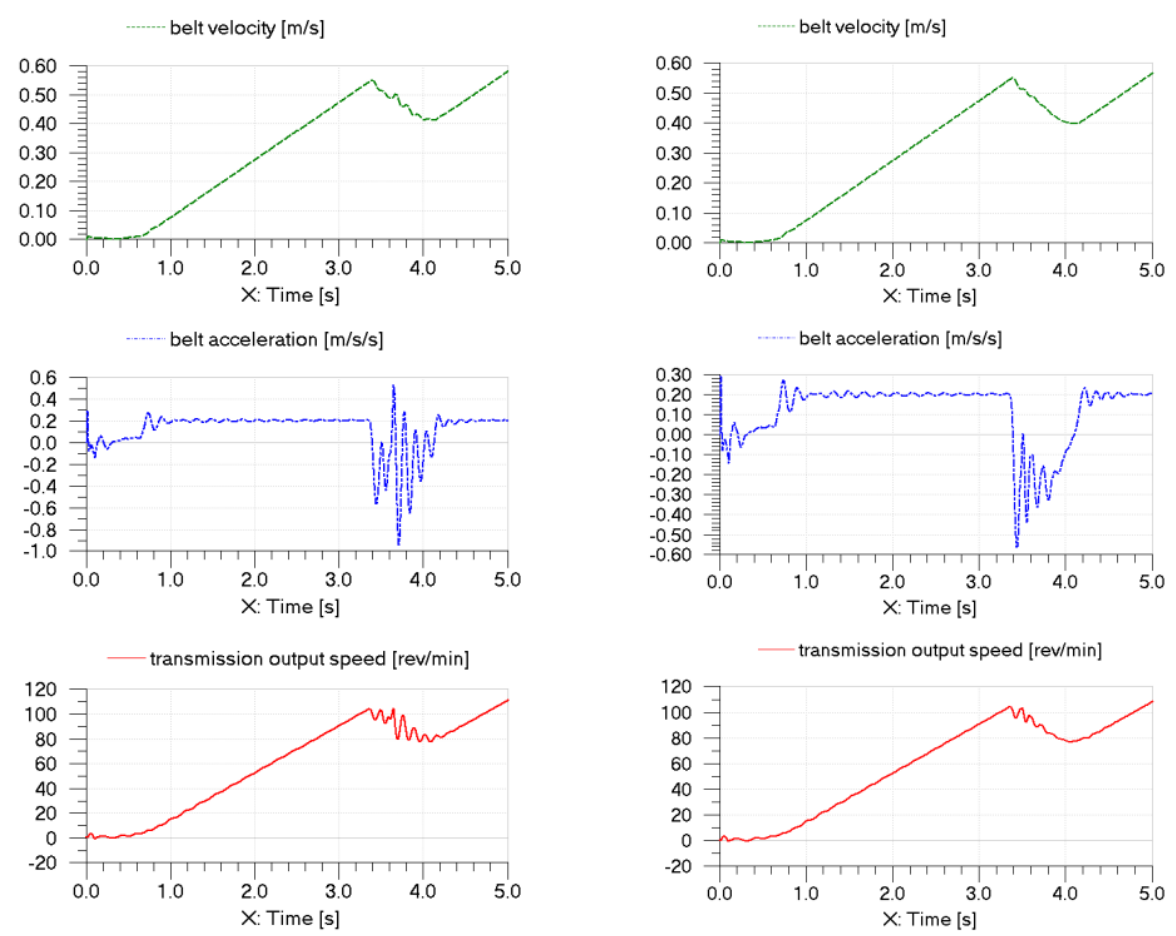

(a) without synchronous control

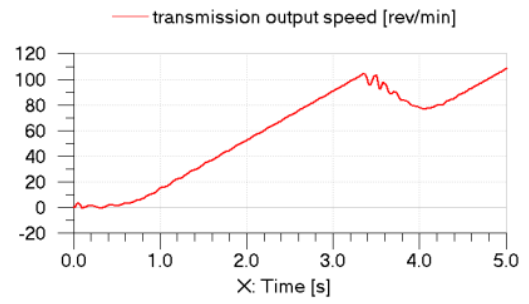

(b) with synchronous control

\section{Figure 5. Simulation Curves During Upshift Process from First Gear to Second Gear}

As is shown in Figure 5, the curves of belt velocity, belt acceleration and transmission output speed under the condition with synchronous control have less fluctuation than that under the condition without synchronous control. Belt acceleration shock with synchronous control is lower clearly than that without synchronous control. The maximum acceleration value is less than $0.6 \mathrm{~m} / \mathrm{s} / \mathrm{s}$ during shift process in Figure $5(\mathrm{~b})$. On the whole, the synchronous shift control for AMT without synchronizer can improve the shift quality obviously during upshift process.

As is betrayed in Figure 6, three methods are offered in downshift simulations. The first method is given under the condition without synchronous control. The second one is provided under the condition with synchronous control by waiting for slowing down the output shaft. The third one is provided under the condition with synchronous control by operating the clutch twice. As can be seen in the pictures, the third method is the best one for downshift process because it reduces two main shift characteristics in terms of the time of downshift process and shifting jerks. Although the second method is simple, it lengthens the time of shift process because the speed loss of the output shaft is more than the other methods. So, the best method is to operate the clutch twice for heavy-duty AMT without synchronizer during downshift process. 

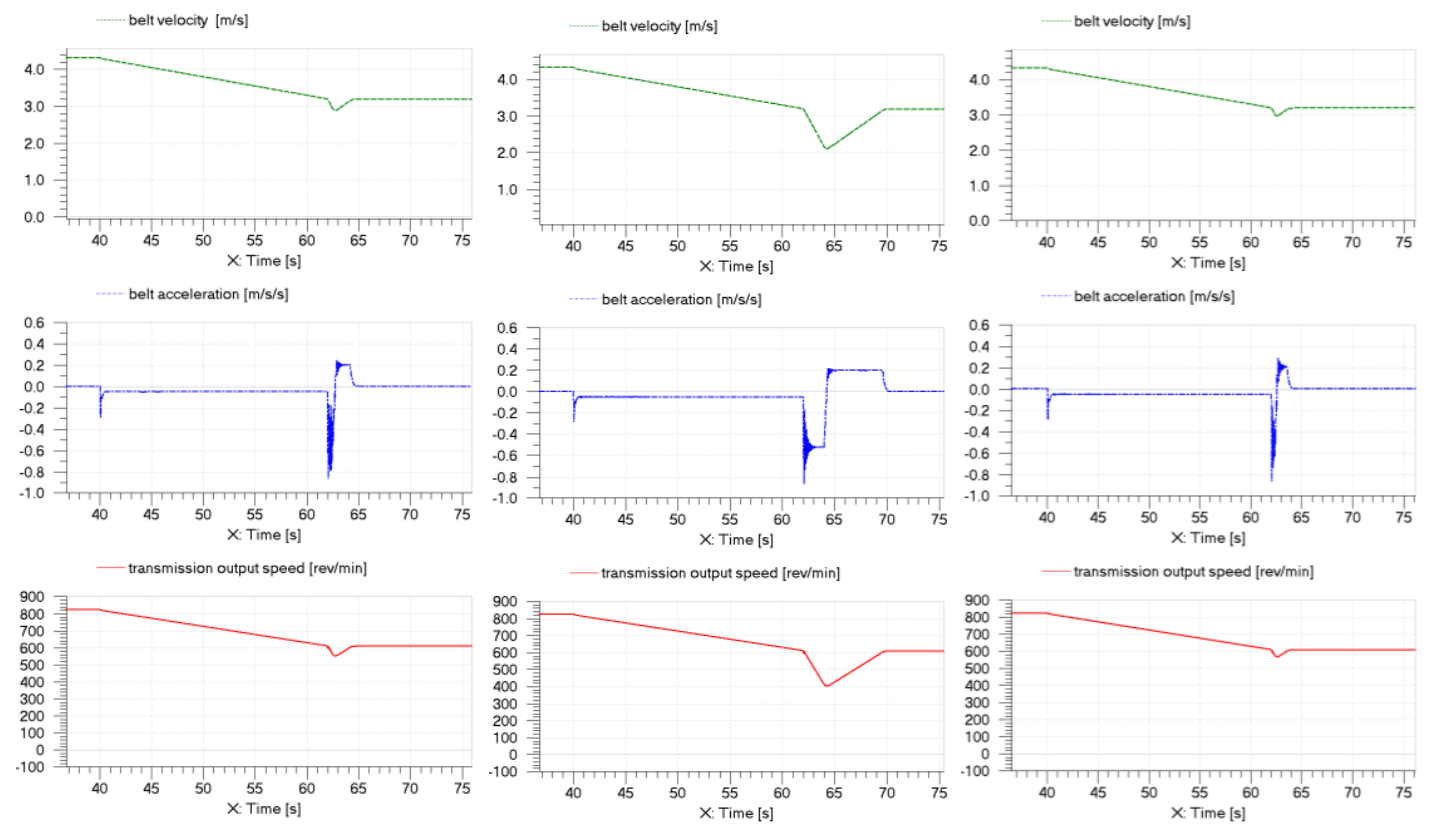

(a) without synchronous control

(b) slowing down the output shaft

(c) operating the clutch twice

\section{Figure 6. Simulation Curves During Downshift Process from Eight gear to Seventh Gear}

\section{Conclusion}

All as in conclusion, heavy-duty AMT without synchronizer driven by three-phase induction motor can be achieved synchronous shift by the use of appropriate control strategy in this paper. Based on the speed analyses concerning the input shaft and the output shaft during both upshift process and downshift process, we find that the control strategy is reasonable to realize synchronous shift by controlling the input shaft. In addition, estimation algorithms of the load equivalent inertia and the load resistance torque at the transmission output shaft are given for AMT's application in belt conveyor's soft starting. Simulation results show that the synchronous shift control strategy is available for heavy-duty AMT without synchronizer which provide a reference to research detailed shift schedule.

\section{Acknowledgements}

This work was supported by the National Natural Science Foundation of China (Grant No. 51174126).

\section{References}

[1] L. Glielmo, L. Iannelli and V. Vacca, "Gearshift control for automated manual transmission", IEEE/ASME Transactions on Mechatronics, vol. 11, no.1, (2006), pp.17-26.

[2] G. Lucente, M. Montanari and C. Rossi, "Modelling of an automated manual transmission system", Mechatronics, vol. 17, (2007), pp.73-91.

[3] F. Vasca, L. Iannelli and A. Senatore, "Torque transmissibility assessment for automotive dry-clutch engagement", IEEE/ASME Transactions on Mechatronics, vol. 16, no. 3, (2011), pp. 564-573.

[4] E. Galvagno, M. Velardocchia and A. Vigliani, "Analysis and simulation of a torque assist automated manual transmission”, vol. 25, (2011), pp. 1877-1886. 
[5] Z. J. Liu, D. T. Qin and J. J. Hu, "Design and application of heavy truck AMT system", Transactions of the Chinese Society for Agricultural Machinery, vol. 42, no. 8, (2011), pp. 7-14.

[6] Q. H. Chen, D. T. Qin and X. Ye, "Optimal control about AMT heavy-duty truck starting clutch", China Journal of Highway and Transport, vol. 23, no. 1, (2010), pp. 116-122.

[7] Z. B. He, H. Y. Chen and J. Q. Xi, "The control strategy and experimental research of an AMT vehicle's clutch in crawl driving condition", China Automotive Engineering, vol. 25, no. 6, (2003), pp. 574-577.

[8] J. He, H. Jin and H. Y. Chen, "Simulation research on control strategy of electromechanic clutch during vehicle starting", China ACTA ARMAMENTARII, vol. 32, no. 8, (2011), pp. 931 - 938.

[9] G. L. Kong, Z. M. Zhong and Z. P. Yu, "A Method of calibration of clutch torque transfer feature based on AMT launch control”, Procedia Engineering, vol. 16, (2011), pp.88-94.

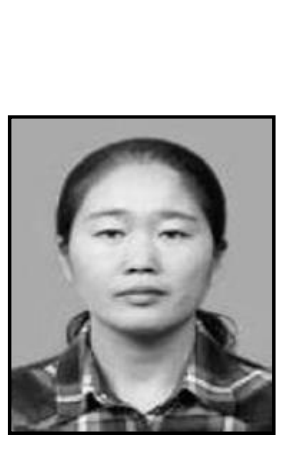

\section{Authors}

\section{Yunxia Li}

She is a doctoral candidate in School of Mechanical Engineering, Shandong University, China. She is interested in theory and control of automated mechanical transmission.

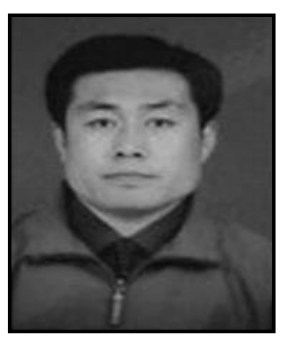

\section{Zengcai Wang}

He is a professor in School of Mechanical Engineering, Shandong University, China. He is interested in vehicle electronic control.

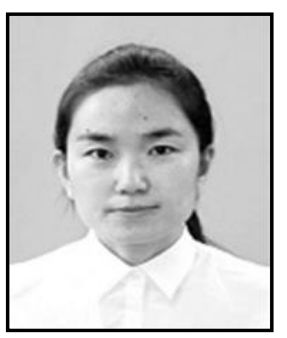

\section{Xiaoyan Cong}

She is a doctoral candidate in School of Mechanical Engineering, Shandong University, China. She is interested in theory and control of automated mechanical transmission. 
International Journal of Control Automation Vol. 7, No. 6, (2014) 